\title{
LNG TANK IN ŚWINOUJŚCIE: NONLINEAR ANALYSIS OF THE TANK DOME ELEMENTS BEHAVIOUR
}

\author{
Bartosz Sobczyk \\ Gdańsk University of Technology, Poland
}

\begin{abstract}
In this paper, the dome of a tank in the Swinoujście LNG terminal is analysed. Some of the rafter ribs at the connection with hangers were not mounted during construction of the tank dome. Therefore, it has become necessary to estimate its response, which has been done with the aid of some computational models of the dome, that have been created in the finite element method environment. Different local models are studied, aiming to recreate possible outermost conditions of the tank dome response, i.e. with or without composite action between steel and concrete parts of the tank dome. Static calculations with material and geometric nonlinearities are carried out on the computational models, enabling the creation of a load capacity envelope of the rafter with or without ribs. The obtained results are then used to decide if repair works need to be done and whether the missing ribs should be welded.
\end{abstract}

Keywords: ultimate capacity, local analysis, nonlinear equilibrium paths, finite element method (FEM)

\section{INTRODUCTION AND RESEARCH BACKGROUND}

The rules and principles of structural mechanics and dynamics govern the behaviour of all structures, regardless of their location and function. Therefore, offshore floating and fixed structures, ships, harbours, docks and their equipment are often treated as constructions made of beams, plates, shells, solids, etc. Such structures and equipment are subjected to loading conditions, that need to be determined carefully, depending on the function of the structure and the environment in which it operates. Appropriate theoretical approaches and computational methods make it possible to build idealized models of the structures, providing insight into their response and properties. Sometimes it is also required to measure the properties of a structure at the site, for example via structural health monitoring. Recent studies reveal that structural analyses of maritime or offshore constructions are still desirable and of interest to researchers and engineers. Selected examples of such studies, that show current trends in this field and deal with the aforesaid issues, are briefly discussed. Response, failure and diagnostics problems of wind turbines and their foundations have been analysed in [1-3]. Application of modern materials like laminated composites or sandwich elements has been considered and tested, as presented in [4-6]. Structural responses in different loading conditions of ships, floating structures and rig equipment have been studied in [7-10]. Structures that enable effective operation and exploitation of docks, shipyards and terminals, such as retaining walls, bridges and tanks, have also been analysed in the field of their response predicted by means of the finite element method (FEM) or methods resulting from sensor measurements [11-14].

The problems considered in this paper are entirely consistent with the research trends described above. A tank, located at the LNG Terminal in Świnojście, shown in Fig. 1, is analysed here. 


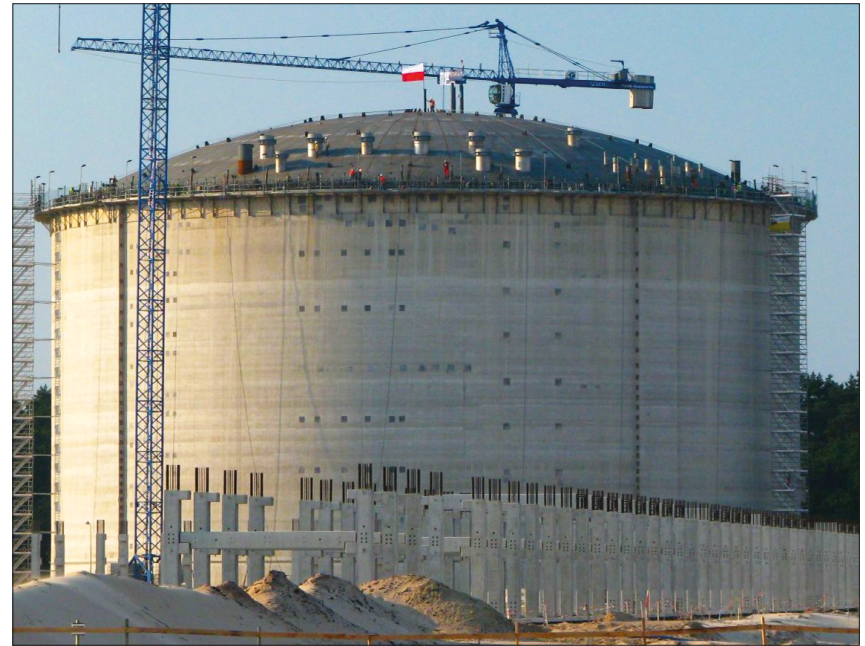

Fig. 1. View of the tank during its construction

Two the same tanks were built at the terminal and are used to store liquefied natural gas (LNG). Each structure includes an inner steel, vertical and cylindrical storage tank with a flat bottom, which is covered with a lightweight aluminium roof sustaining thermal insulation. The storage tank has a capacity of $160000 \mathrm{~m}^{3}$. The aluminium roof is suspended by hangers from a tank dome. The external structure is also vertical, and cylindrical and its walls are made of post-tensioned concrete. It is covered by the dome, which is made of steel IPE300 radial rafters and HEB240 circumferential purlins, that form a steel grillage. Steel sheets are welded to the rafters and purlins to close the roof surface. The steel sheets serve as a stay-in-place (SIP) formwork and gas-tight insulation of the concrete shell, being the topmost element of the dome. Shear studs are placed on the steel sheets to connect the steel and the concrete parts of the dome. The thickness of the part of the dome made of concrete ranges from $800 \mathrm{~mm}$ at the intersection with the vertical walls to $400 \mathrm{~mm}$ at the crown. The scheme of the tank cross-section with its basic dimensions is shown in Fig. 2. A picture taken from the lightweight roof (Fig. 3) shows the underside of the dome.

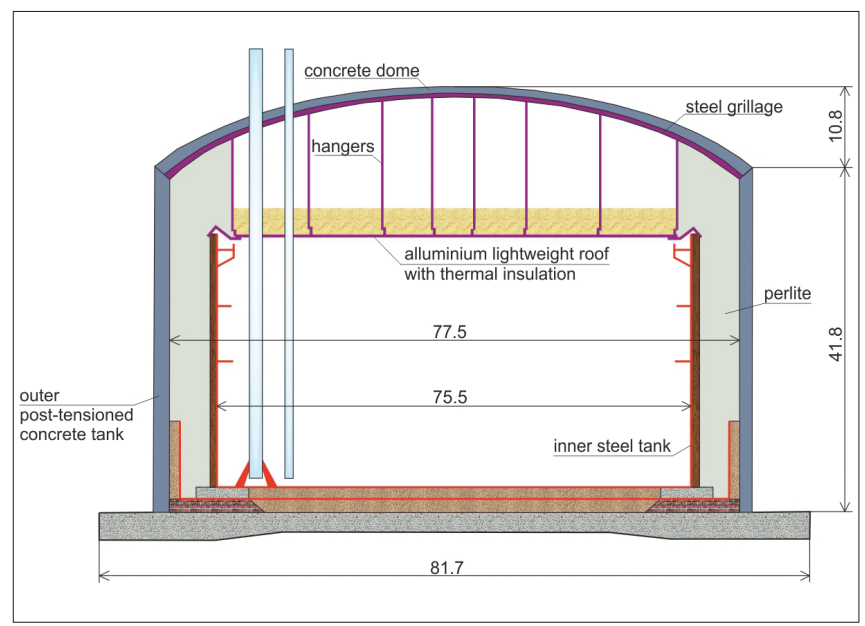

Fig. 2. Tank cross-section (dimensions in [m])

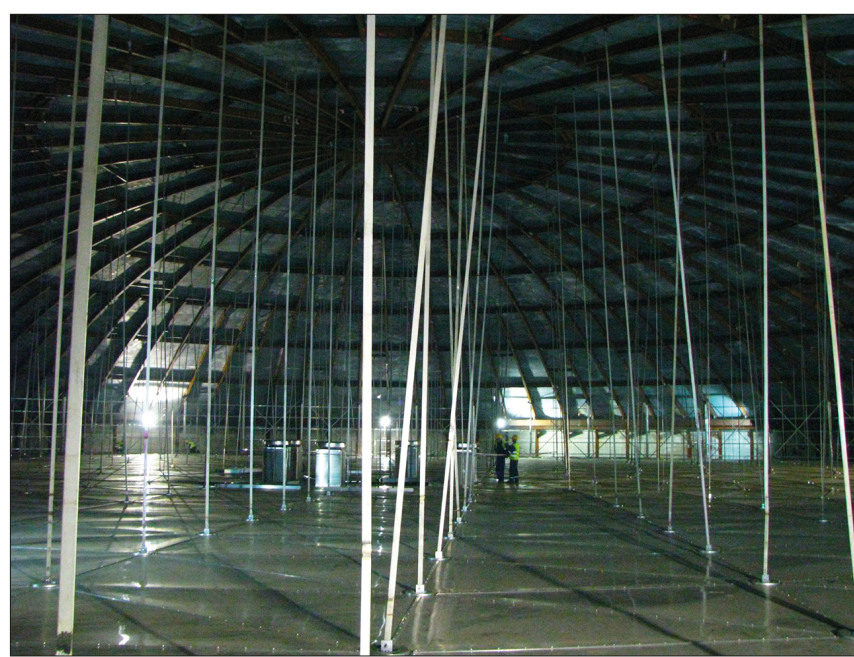

Fig. 3. Underside of the dome and the lightweight inner aluminium roof

During construction of the steel grillage, approximately $25 \%$ of the total number of the rafter ribs that had been designed were not welded. The ribs should have stiffened the rafter at the connection with the hangers of the lightweight roof. The detail of this connection is shown in Fig. 4. The missing rib is coloured in purple.

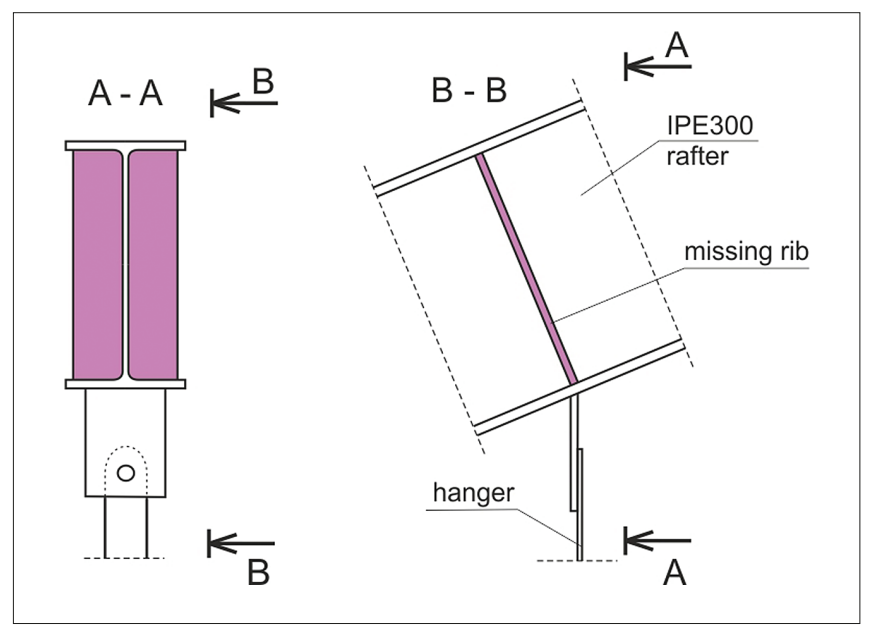

Fig. 4. Rafter-hanger connection

This defect was found after the steel grillage had been mounted above the tank. The cost of eventual repair and assembly of the missing ribs would be relatively high, as the work would need to be done by industrial climbers. It was not possible to build scaffolding (enabling easy installation of the ribs) on the lightweight roof due to its insufficient load capacity under additional temporary loading conditions. It is worth mentioning that IPE300 rafters should be rather resistant to the stability loss even when the webs are not additionally stiffened. It can also be stated that the hangerbeam connection detail, presented in Fig. 4, is a standard one. It is proposed by many engineers and treated as a typical solution, although possibly there is no need to add stiffening due to real loading conditions. Nevertheless, because the ribs were included in the design project, the investor wanted to check if it is, in fact, necessary to mount them or instead 
perhaps unnecessary or unjustified because of the cost. Therefore, before the decision about the repair was made, computational analyses of the dome response were done, to check this issue.

In this paper, the attention is focused on the dome response calculations. Computational models are shown that allow estimation of the dome failure risk when the ribs are not welded. On this basis it is possible to draw conclusions about the repair work. This paper is in a sense a continuation of work [15] in which a simplified analysis was done, for which the simulations were made under the assumption that there would be no composite action between the steel grillage and the concrete shell. New results are presented here, and this effect is now taken into consideration.

\section{ANALYSIS METHODS}

Decisions about the choice of theoretical approaches that are used to create a computational model of a structure and types of analyses to be carried out are crucial. These have to be done with great care and are usually influenced by the time and resources that can be spent on the task solution, as well as by the level of results precision to be achieved. The methods, models and approaches that are used to estimate the response of the tank dome elements are presented in this paper. They are chosen in a way to enable a clear decision whether the missing rafter ribs are essential to maintain safety of the whole dome.

The tank description (above and shown in Fig. 2 - Fig. 4) reveals that its structure is quite complicated. Additionally, because of the construction technology, there are uncertainties about the response of the dome, mainly related to the stiffness of the connection between their parts. Shear studs were constructed on the steel SIP sheets, and therefore a composite action between the steel and concrete parts of the dome should have occurred. Similarly, the stiffness of the connections between elements of steel grillage is not precisely clear, as for example some of them use a combination of bolts and welds (flanges of rafters are welded, while their webs are bolted), and in others only bolts are used (this applies to the purlinrafter connection) [16]. Therefore, the elements of the dome can be treated neither as hinged nor as continuous. Thus, estimation of the response of the whole structure, although possible, would require many stages and loading conditions to be considered. As a result, parametric analyses should be done, due to the connection stiffness issues and the other uncertainties described above. In such a case significant time and resources would be needed to obtain the solution.

On the other hand, the ribs (Fig. 4) are used to ensure stability of the rafters' webs and to strengthen the connection with hangers. Their role is to provide local load capacity only, and they do not contribute to the global stiffness of the whole tank. Therefore, it seems that it is justified to conduct some local analyses of the behaviour of representative parts of the dome. It is important that this reduces the effort to obtain a solution. Here the local analyses are done on models with and without ribs. As composite action could have occurred between the steel and concrete parts of the dome, the theoretical response is studied, both taking the concrete shell into account and neglecting it. This allows to study the possible outermost stiffness conditions of the local models: on the one hand, conservative and the most unfavourable, so that only the steel parts of the dome are modelled, and on the other hand favourable, assuming that there is full composite action and no slippage between the dome elements, due to the presence of shear studs. It is expected that the real response will be somewhere between these two scenarios. In the case of local analyses, the computational model boundary conditions are very important, as they significantly influence the results. Because the stiffness of the steel rafters' or purlins' real connections is hard to estimate and also because of the problem of composite action between steel and concrete parts of the dome, outermost conditions are applied to the boundaries. Therefore, different variants of local models are considered, which are either simply supported or fully fixed on the outer edges of the models.

The problems of load capacity and stability are now considered, hence nonlinear static analysis of the system is the choice for the type of calculations to be done. If a decision has to be made about the additional repairs and welding of the missing ribs, the local load capacity of the rafter with and without ribs should be estimated. The local failure of the beam in the area of the connection with the hanger can be caused only by increasing load in the hanger, because of a specific structure and loading conditions of the tank. In consequence, if a rib is missing, the lower flange subjected to increasing load in the hanger would undergo plastic deformations, which could negatively affect the structure. If such an accidental increase of the force in the hanger is analysed, the initial state of stress in the dome elements resulting from permanent loads, live loads and other conditions has to be considered, because it will affect the load capacity of the rafter.

According to these considerations, two-stage static analyses are carried out on different local models representing steel grillage with or without the concrete shell, taking into account the problematic rib or not, with simply supported or fixed conditions assigned to the boundaries of the models. During the first stage of calculations, a state of stress corresponding to the ultimate limit state (ULS) design situations according to [16] is recreated. To determine this condition, internal forces taken from ULS envelopes are applied to the model boundaries, and static analysis is done. The resulting state of stress is then saved and treated as initial input data for all the finite elements in the model during the second stage of analysis. Then, an increase of the force in the hanger is simulated. All degrees of freedom of the nodes located on the lower half of the bolt hole edge in the gusset plate are constrained to the rigid body motion of a single reference point in the centre of the bolt connection. A translation " $U$ " in the downward axis direction of the hanger is applied to the reference point. The scheme of this constraint is shown in Fig. 5. Such an approach enables simulation of the eventual force increase in the hanger. The distribution of loads from the hanger, transferred to the gusset plate via the bolt, is simplified. It is assumed that in 
the unlikely event of an increase of the hanger force, the bolt will move in the downward direction and it will interact with the lower half of the bolt hole edge in the gusset plate. Thus, the two-stage calculations are realized according to the following rule, $\mathbf{g}+\lambda$ pref, where $\mathbf{g}$ represents the loads which are applied to the hanger according to the ULS (initial state), pref is the force in the hanger according to the ULS, and $l$ is the hanger force multiplier, enabling to consider its hypothetical increase. Static calculations with material and geometric nonlinearities are done here. The material nonlinearities are applied in steel elements only (ideally plastic material law), whereas the problem of eventual concrete failure is omitted. Newton's method is used for the purpose of solving nonlinear equilibrium equations [17]. The moment of initiation of plastic deformations in the elements of the steel grillage is captured, and the rafter failure mechanism is determined as well.

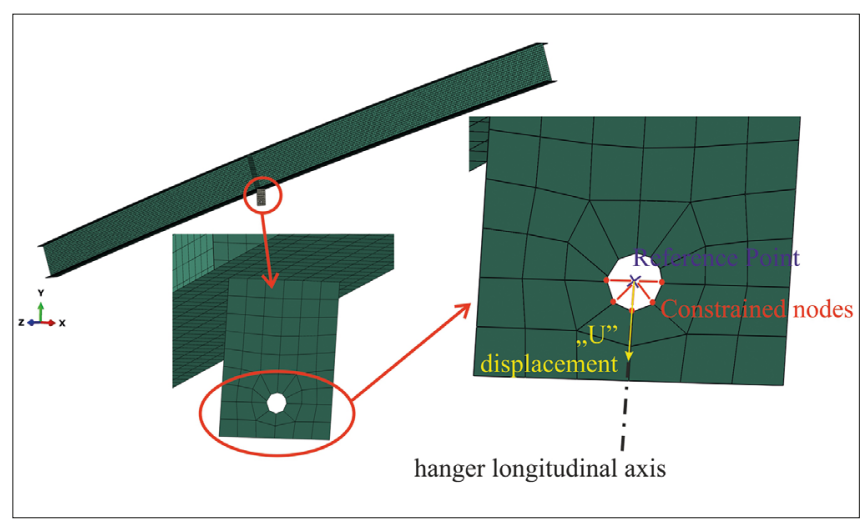

Fig. 5. Gusset plate detail. Realisation of force increase in hanger during $2^{\text {nd }}$ stage of static nonlinear calculations: purple $x$ (reference point), red lines (kinematic constraint), and yellow arrow direction of the increasing translation

As a result of static analyses done on different variants of local models with distinct, outermost boundary conditions, an envelope of the rafter load capacity is created. Obviously, now all the problematic parts of the dome should be analysed. However, here the results for one hanger are presented, as it is intended to focus mainly on the approach that can be used to solve such a problem. It is worth mentioning that a similar analysis was done in [15]. However, in [15] the authors did not take into consideration any eventual composite action between the steel grillage and the concrete shell, which is done in the current study.

All the local models are created in the FEM [18] environment, using Abaqus 6.14 code [17]. The part of the dome selected for the analysis is shown in Fig. 6, in which the location of the analysed hanger is indicated with a red dot. The outer boundaries of the local models with the concrete shell are defined by the axes of rafters and purlins, which are adjacent to the analysed hanger (blue lines in Fig. 6). For the case of the model without the concrete shell, only the rafter between two purlins adjacent to the analysed hanger is considered. Full-integration S4 shell elements are used to build both steel and concrete parts of the computational domain. In order to consider the full composite action between the concrete shell and the steel rafter, all degrees of freedom of the nodes created on the top flange of the rafter are tied with the ones that have been created on the adjacent part of the concrete shell. Therefore, it is assumed that the interface between the rafter top flange and the steel shell is a fixed connection. It needs to be emphasized that the hanger and the gusset plates are not included in the computational domain. The ultimate tensile capacity of the hanger and gusset plate, however, is later compared with the capacity of the rafter or the composite. Such an approach has been applied to determine the eventual margin of safety of the rafter in the unlikely event of a hanger force increase, which is very important regarding the evaluation of whether the ribs should be mounted or not.

The mesh of finite elements in all cases is very fine in order to allow appropriate calculations of plastic deformations. A mesh convergence study was undertaken, and visualisations of the models with and without the concrete shell are shown correspondingly in Fig. 7 and Fig. 8.

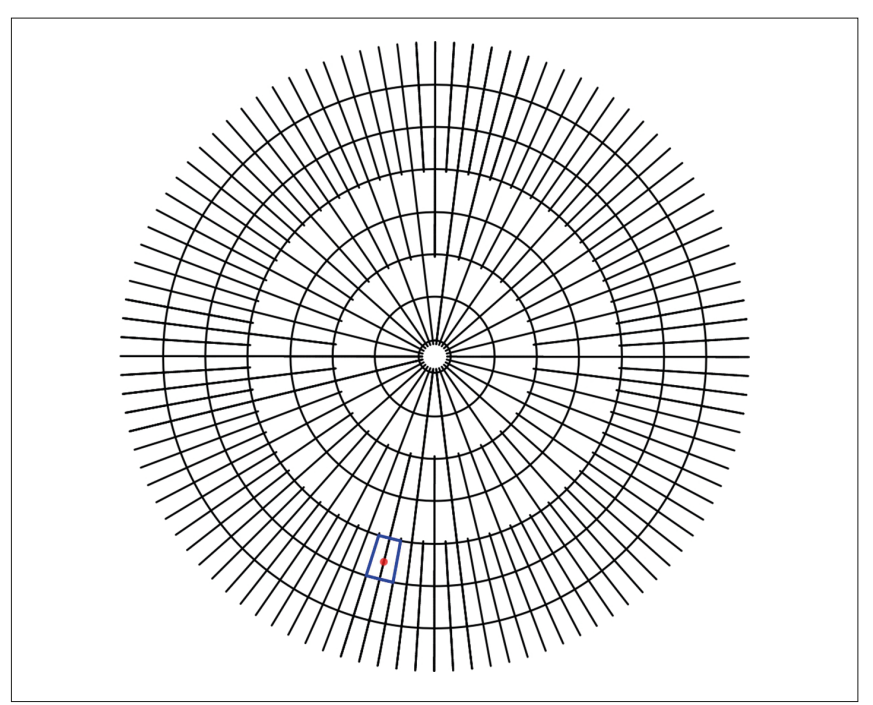

Fig. 6. Plan view of steel grillage, analysed hanger (red dot) and outer boundaries of the local model (blue lines)
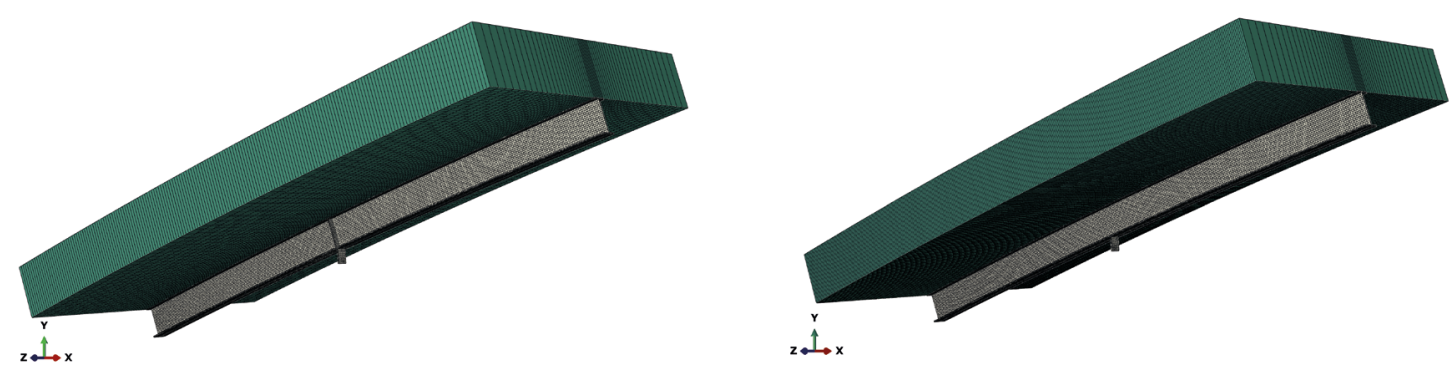

Fig. 7. Visualisation of the computational local models with full composite action between concrete shell (green) and rafter (grey) with rib (left) and without rib (right). Rendering of shell thickness is turned on 

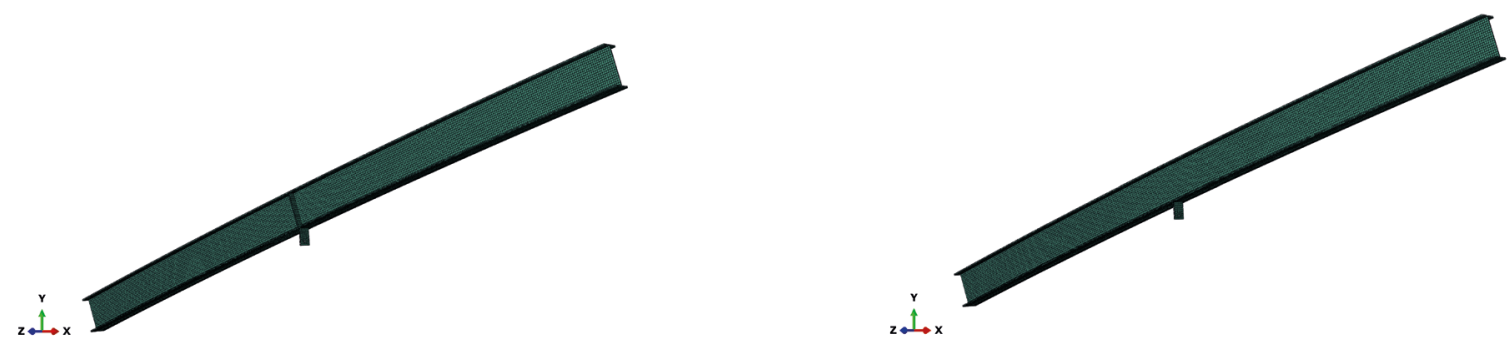

Fig. 8. Visualisation of the computational local models without concrete shell, with rib (left) and without rib (right). Rendering of shell thickness is turned on

The steel grillage has been made from S275 steel. It is treated as homogenous, isotropic, ideally plastic material, for which the elastic modulus is E $=205 \mathrm{GPa}$, Poisson's ratio is equal to 0.3 and the yield strength is $275 \mathrm{MPa}$. The concrete shell has been built of C50/60 concrete. Because concrete failure is not considered in this study, only its elastic properties are reflected. It is assumed that the shell is homogenous and isotropic and has an elastic modulus equal to $\mathrm{E}=37 \mathrm{GPa}$ and a Poisson's ratio of 0.2 .

\section{RESULTS AND DISCUSSION}

As a result of the analyses described above, detailed insight into the dome elements' responses is possible. The relation between increasing force in the hanger, as a function of the hanger connection displacement "U" (Fig. 5) along its axis, is plotted in Fig. 9 - Fig. 12, correspondingly for two models: with the concrete shell with simply supported or fixed boundaries, and without the concrete shell with simply supported or fixed boundaries. All the force-displacement relations shown in Fig. 9 - Fig. 12 start from a certain value of hanger axial force, denoted as axial force in hanger ULS. This is because of the initial state of stress, a consequence of all the loading conditions applied to the steel grillage according to the design, that can affect the dome response. Thus, the analysis begins from the moment when the steel grillage is subjected to the most unfavourable combination of internal forces, according to the ULS envelopes presented in the detailed design [16]. The actions contributing the most to the unfavourable combination are the self-weight of the steel grillage, the dead load of the aluminium lightweight roof and additional maintenance live load distributed on the lightweight roof or on the dome. This is because of the dome construction stages and assembly technology: the steel grillage was mounted on the ground, lifted to its position with the aid of pressure generated inside the tank, and attached to the tank walls; then another stage of tank pressurization was done to enable compensation of the grillage deflections when the concrete of the shell was poured. In consequence, when the concrete reached its full effective strength and the pressure was released, the steel grillage started to carry itself, the lightweight roof and eventually the additional live load. The wind and snow loads did not contribute significantly to the state of the internal forces. Moreover, there are vents in the lightweight aluminium roof; therefore, the tank dome cannot be sucked inside the structure, and additional loads resulting from these effects are not considered.

For the considered part of the dome, the initial axial force in the hanger equals approximately 8 kN. In Fig. 9 - Fig. 12 the moment of rafter yielding initiation is indicated, which occurs when the steel yield strength is achieved in the first finite element of the computational domain. Finally, the load corresponding to the failure of the hanger and the gusset plate is also shown in Fig. 9 - Fig. 12. According to [16], this load equals $45.5 \mathrm{kN}$.

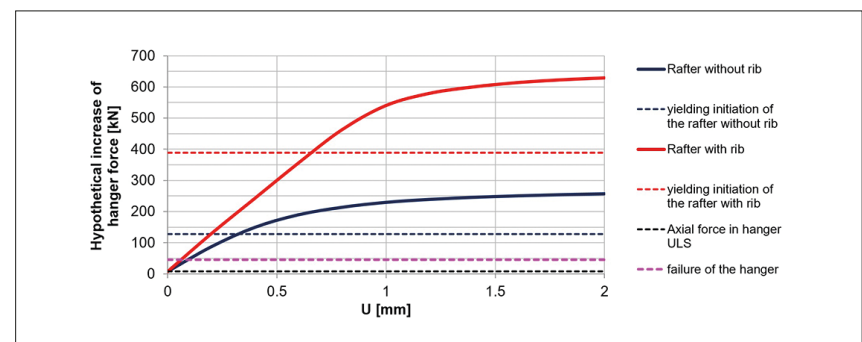

Fig. 9. Axial force in hanger as a function of the hanger connection displacement " $U$ " for the local model with concrete shell, for which the boundaries are simply supported

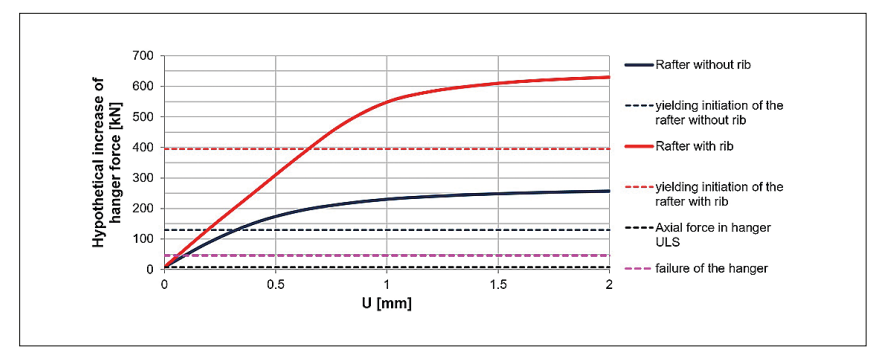

Fig. 10. Axial force in hanger as a function of the hanger connection displacement "U" for the local model with concrete shell, for which the boundaries are fixed

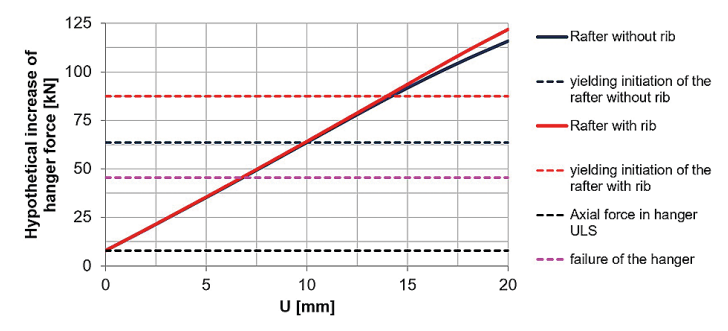

Fig. 11. Axial force in hanger as a function of the hanger connection displacement "U" for the local model without concrete shell, for which the boundaries are simply supported 


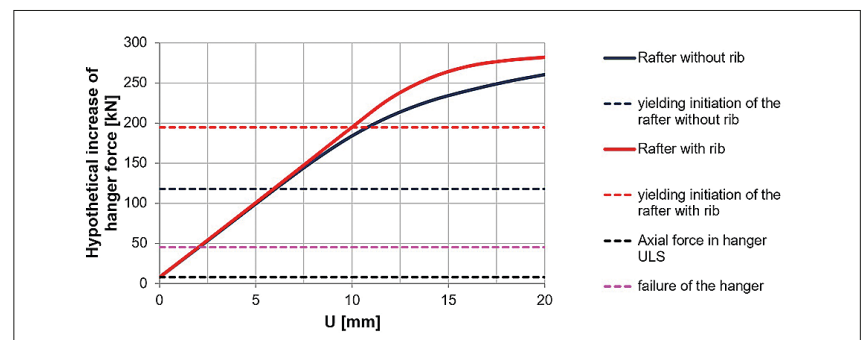

Fig. 12. Axial force in hanger as a function of the hanger connection displacement "U" for the local model without concrete shell, for which the boundaries are fixed
In Fig. 13 - Fig. 16, contours of the Mises stresses are shown for all the variants of local models at the end of the static analyses. They indicate that in the models without the concrete shell, due to the unconstrained upper flanges of rafters, they are bent, and consequently plastic hinges are observed in the areas of extreme moments. If composite action between steel grillage and concrete shell is considered, due to the additional stiffness of the concrete, the estimated deformations are much smaller than in the aforesaid case, and high local stress in the area of the hanger connection causes the failure.

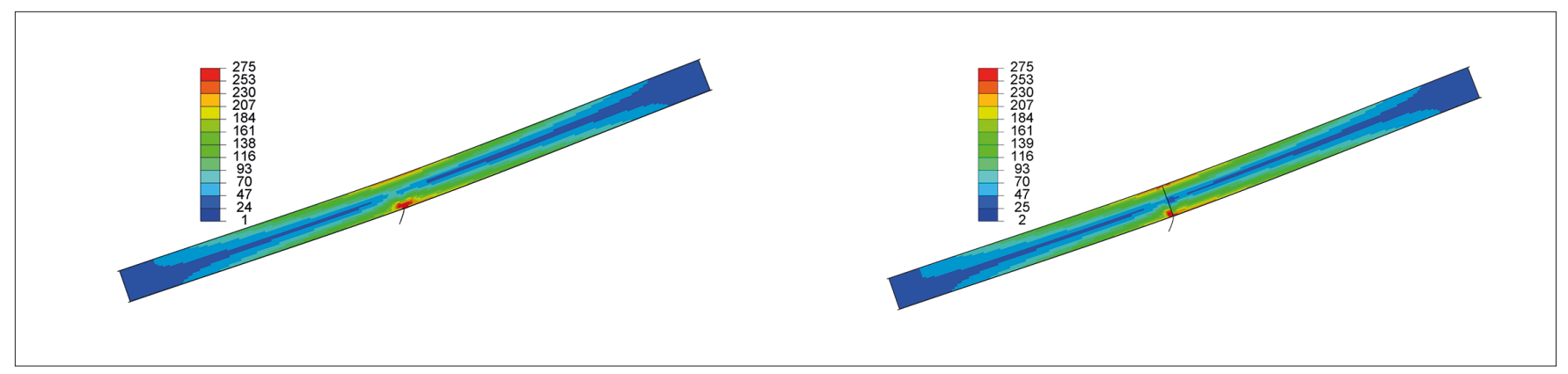

Fig. 13. Contours of the Mises stress [MPa] at the end of the analysis for the models without concrete shell, with simply supported boundaries, without (left) or with (right) the rib

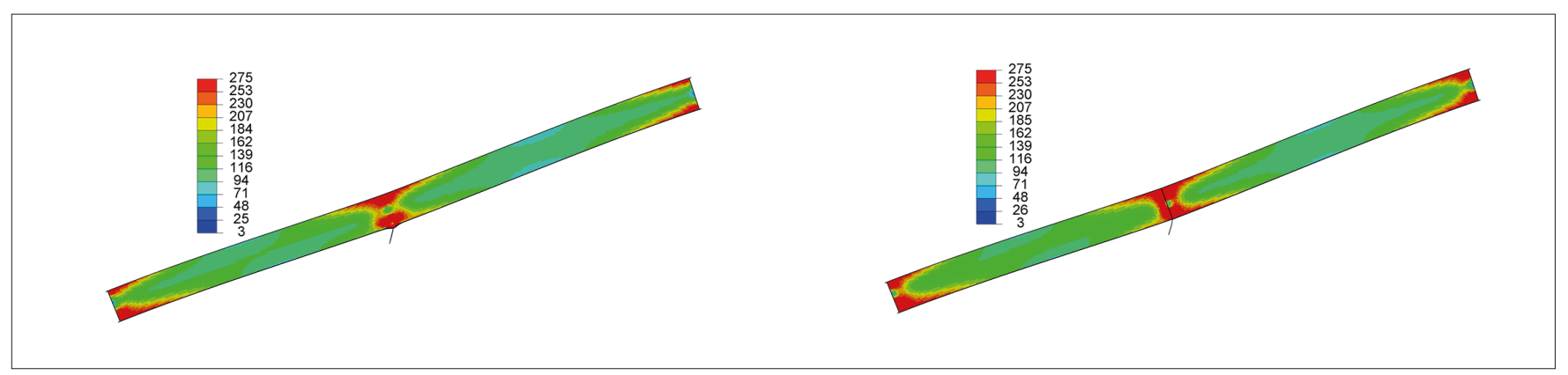

Fig. 14. Contours of the Mises stress [MPa] at the end of the analysis for the models without concrete shell, with fixed boundaries, without (left) or with (right) the rib
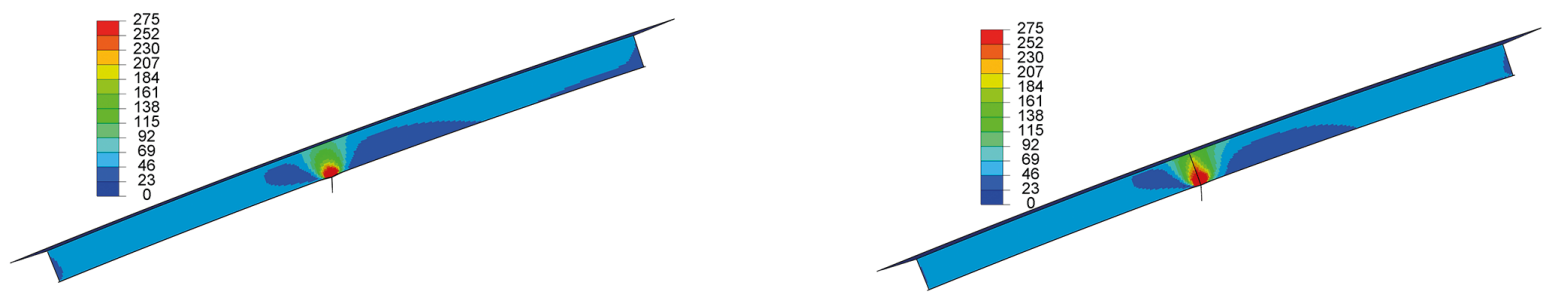

Fig. 15. Contours of the Mises stress [MPa] at the end of the analysis for the models with concrete shell, with simply supported boundaries, without (left) or with (right) the rib
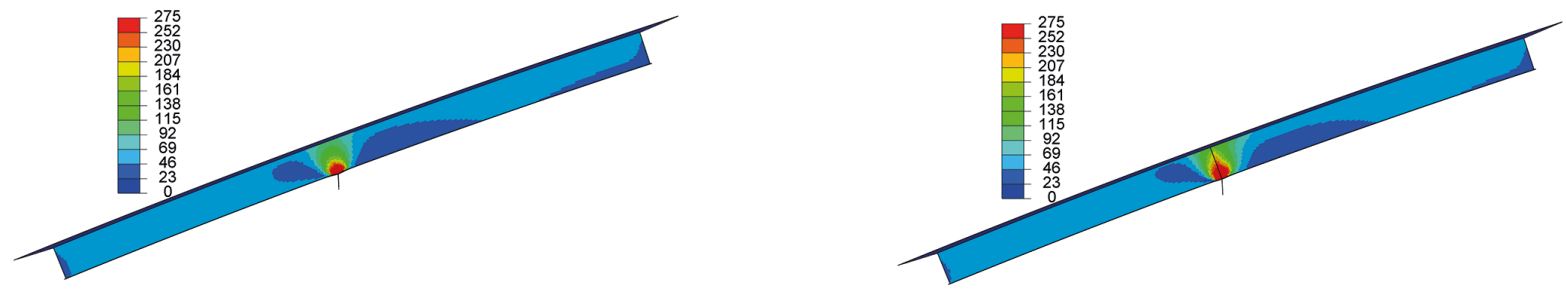

Fig. 16. Contours of the Mises stress [MPa] at the end of the analysis for the models with concrete shell, with fixed boundaries, without (left) or with (right) the rib 
The force-displacement paths presented in Fig. 9 - Fig. 12 reveal that the models without the analysed rib experience yielding much earlier than the ones with ribs, which was expected. The yielding initiation values are collected in Tab. 1.

Tab. 1. Hypothetical forces in the hanger, that lead to yielding initiation of the rafter in all the considered local models

\begin{tabular}{|c|c|c|c|c|}
\hline \multirow{2}{*}{ Type of model } & \multicolumn{3}{|c|}{$\begin{array}{c}\text { Hypothetical force in the hanger resulting in } \\
\text { initiation of rafter yielding [kN] }\end{array}$} \\
\cline { 2 - 5 } & \multicolumn{2}{|c|}{ fixed BCs } & \multicolumn{2}{c|}{ simply supported BCs } \\
\cline { 2 - 5 } & $\begin{array}{c}\text { with } \\
\text { rib }\end{array}$ & $\begin{array}{c}\text { without } \\
\text { rib }\end{array}$ & $\begin{array}{c}\text { with } \\
\text { rib }\end{array}$ & $\begin{array}{c}\text { without } \\
\text { rib }\end{array}$ \\
\hline $\begin{array}{c}\text { without concrete } \\
\text { shell }\end{array}$ & 195 & 118 & 88 & 64 \\
\hline $\begin{array}{c}\text { with concrete } \\
\text { shell }\end{array}$ & 395 & 130 & 389 & 127 \\
\hline
\end{tabular}

For the rafters without ribs and without the concrete shell, the envelope of yielding initiation ranges from $64 \mathrm{kN}$ to $118 \mathrm{kN}$. These values are correspondingly 1.42 to 2.62 times greater than the plastic resistance of the hanger crosssection $(45.5 \mathrm{kN})$. If the composite action between the steel grillage and the concrete shell is considered and the rafters without ribs are investigated, the yielding initiation envelope ranges from $127 \mathrm{kN}$ to $130 \mathrm{kN}$, which is correspondingly 2.79 to 2.86 times greater than the load capacity of the hanger. Thus, a very important conclusion can be drawn. The onset of plastic deformation in rafters without ribs in all the considered variants, i.e. including or neglecting composite action between the concrete shell and the steel grillage, is always beyond the resistance of the hanger and gusset sheet to tension forces. This means that if hypothetically the force in the hanger is accidentally increased, dangerous deformations or plastic yielding of the rafter in the area of the connection with the hanger will not occur. Instead, in the unlikely event of such a load increase, the hanger would break while the steel grillage, being a part of the dome, would remain undamaged. It is also worth mentioning that Tab. 1 presents results from models created to reflect outermost conditions: conservative in the case of steel elements only, and highly favourable including full composite action between the steel grillage and the concrete shell. In reality the response of the dome would be somewhere between these two conditions.

Here, only one, selected part of the dome has been analysed. If the attention is focused on the lowest estimated load capacity of the rafters without ribs under increasing loads in the hangers, i.e. neglecting the composite action, one may refer also to [15]. In [15] all the representative parts of the analysed tank dome are analysed, showing that for such a particular approach the loads causing rafter yielding initiation are always greater than the load capacity of the hanger. Therefore, the safety of the steel grillage is ensured. The results from the current analysis, showing that the yielding loads are greater in the case when the dome is treated as a steel-concrete composite compared to the analysis in which the concrete shell is neglected, are combined with the previous conclusions [15]. In consequence, it is concluded that there exists a margin of safety for failure of the rafters without ribs and that they are not susceptible to damage even if an increase of load in the hanger were to happen. This means that the repair work of the tank dome is not needed, and expensive additional work does not have to be done.

\section{CONCLUSIONS}

In this study, analysis of the behaviour of the Swinoujście LNG terminal tank dome elements has been done. Because during the construction of the tank some ribs of the dome's steel grillage rafters were not assembled, static numerical simulations were carried out here to predict the dome response. Different variants of local computational models with and without the problematic ribs, aiming to describe all the possible outermost conditions of structure response, were studied in order to determine the envelope of the rafters' load capacity under hypothetically increasing load in the attached hangers. The calculations revealed that the lowest estimate of load capacity, determined for the most conservative model in which the composite action is neglected, is greater than the load capacity of the hanger. This shows that if the hanger axial force accidentally increases, plastic deformations of the rafter elements in the area of connection with the hanger will not occur, because the hanger will fail much sooner. Additionally, local load capacity of the rafter, assuming full composite action between the concrete shell and the steel grillage, is much greater than in the conservative condition, determined on the model in which only the steel part is loaded. The real response of the structure is somewhere between these two situations. Some previous analyses [15] done for all the representative parts of the analysed tank, assuming conservatively that there is no composite action between the steel grillage and the concrete shell, revealed that for such a particular approach the loads causing yielding initiation of rafters without ribs are always greater than the load capacity of the hanger. The present study shows that this difference is even greater due to the composite action. The rafters without ribs can easily carry increased loads, greater than the resistance of the hanger cross-section to tension, and hence there is quite a large margin of safety. Although the hanger-rafter connection is not stiffened, it allows appropriate distribution of loads during the lifetime of this structure. Thus, in view of the actual and previous analyses, it can be stated that the safety of the steel grillage-hanger connection is ensured, although nearly $25 \%$ of the ribs were not assembled.

In view of these results, a question can be asked as to whether it is always necessary to apply stiffening ribs in structural details similar to those considered here. Such ribs are used by many engineers and treated as a typical solution, although possibly in some situations there is no need to add stiffening due to real loading conditions. As a consequence of project time limitations and the fast-paced work environment in the design offices, engineers do not check every detail of the designed structure. In this case, from the mechanical point of view, the tank dome can maintain safe operation conditions when the ribs are not mounted. Therefore, some 
cost savings could have occurred, and the ribs should not have been designed and mounted. On the other hand, the site supervisors did not ensure appropriate quality of the work regarding this detail, and thus additional resources had to be spent to determine whether repair work was required. Therefore, great attention should be paid to the supervision of the structural design process and construction work in order to avoid such mistakes, that can sometimes significantly increase the duration of a project.

\section{ACKNOWLEDGEMENTS}

Abaqus calculations were carried out at the Academic Computer Centre in Gdańsk.

\section{REFERENCES}

1. M. Alonso-Martinez, J.M. Adam, F.P. Alvarez-Rabanal and J.J. del Coz Díaz. 'Wind turbine tower collapse due to flange failure: FEM and DOE analyses', Engineering Failure Analysis. 2019, 104:932-49. doi: 10.1016/j.engfailanal.2019.06.045.

2. X. Yang, X. Zeng, X. Wang, J. Berrila and X. Li. 'Performance and bearing behavior of monopile-friction wheel foundations under lateral-moment loading for offshore wind turbines', Ocean Engineering. 2019, 184:159-72. doi: 10.1016/j. oceaneng.2019.05.043.

3. Z. Liu and L. Zhang. 'A review of failure modes, condition monitoring and fault diagnosis methods for large-scale wind turbine bearings', Measurement. 2020, 149:107002. doi: 10.1016/j.measurement.2019.107002.

4. J. Chróścielewski, M. Miśkiewicz, Ł. Pyrzowski and K. Wilde. 'Composite GFRP U-Shaped Footbridge', Polish Maritime Research. 2017, 24:25-31. doi: 10.1515/pomr-2017-0017.

5. Ł. Pyrzowski. 'Testing contraction and thermal expansion coefficient of construction and moulding polymer composites', Polish Maritime Research. 2018, 25:151-8. doi: 10.2478/pomr-2018-0036.

6. N. Kharghani and C. Guedes Soares. 'Experimental and numerical study of hybrid steel-FRP balcony overhang of ships under shear and bending', Marine Structures. 2018, 60:15-33. doi: 10.1016/j.marstruc.2018.03.003.

7. C.M. Wang, T.Y. Wu, Y.S. Choo, K.K. Ang, A.C. Toh, WY. Mao et al. 'Minimizing differential deflection in a pontoon-type, very large floating structure via gill cells', Marine Structures. 2006, 19:70-82. doi: 10.1016/j.marstruc.2006.06.002.

8. Y.G. Cao and S.H. Zhang. 'Failure analysis of a pinion of the jacking system of a jack-up platform', Engineering Failure Analysis. 2013, 33:212-21. doi: 10.1016/j. engfailanal.2013.05.018.
9. H. Qin, L. Mu, W. Tang and Z. Hu. 'Numerical study on structural response of anti-sloshing baffles of different configurations in a sloshing tank considering hydroelasticity', Ocean Engineering. 2019, 188:106290. doi: 10.1016/j. oceaneng.2019.106290.

10. A. Tatsumi and M. Fujikubo. 'Ultimate strength of container ships subjected to combined hogging moment and bottom local loads part 1: Nonlinear finite element analysis', Marine Structures. 2020, 69:102683. doi: 10.1016/j. marstruc.2019.102683.

11. Ł. Pyrzowski, M. Miśkiewicz and J. Chróścielewski. 'The effect of fishing basin construction on the behaviour of a footbridge over the port channel', Polish Maritime Research. 2017, 24:182-7. doi: 10.1515/pomr-2017-0037.

12. M. Miśkiewicz, Ł. Pyrzowski, K. Wilde and O. Mitrosz. 'Technical monitoring system for a new part of Gdańsk deepwater container terminal,' Polish Maritime Research. 2017, 24:149-55. doi: 10.1515/pomr-2017-0033.

13. M. Sondej, C. Ratnayake and M. Wójcik. 'Economical and safe method of granular material storage in silos in offshore port terminals', Polish Maritime Research . 2018, 25:62-8. doi: 10.2478/pomr-2018-0097.

14. H. Jeong and W.J. Shim. 'Calculation of boil-off gas (BOG) generation of KC-1 membrane LNG tank with high density rigid polyurethane foam by numerical analysis', Polish Maritime Research. 2017, 24:100-14. doi: 10.1515/ pomr-2017-0012.

15. M. Miśkiewicz, J. Chróścielewski, B. Sobczyk, Ł. Pyrzowski and K. Wilde. 'Verification of rafter strenghtening in the gas tank roof', Proceedings of the 27th Conference on Structural Failures, Szczecin-Międzyzdroje. 2015, p. 253-60.

16. Saipem S.P.A. Detailed design of roof framing for LNG tanks package LNG tank TK-2011 and TK-2012. 2012.

17. Dassault Systèmes Simulia Corp. Abaqus 6.14 Documentation, Dassault Systèmes, Providence, RI, USA, 2014.

18. M.G. Larson and F. Bengzon. The finite element method: Theory, implementation, and applications. vol. 10 Berlin, Heidelberg: Springer Berlin Heidelberg. 2013. doi: 10.1007/978-3-642-33287-6. 
CONTACT WITH THE AUTHOR

Bartosz Sobczyk

e-mail: bartosz.sobczyk@pg.edu.pl

Gdańsk University of Technology

Narutowicza 11/12

80-233 Gdańsk

Poland 